\title{
Four lessons from my very early days in crystallography: The lasting impact of a few selected 'first structures' on my path in science B Foxman ${ }^{1}$ \\ ${ }^{1}$ Chemistry MS015, Brandeis Universtiy foxman1@brandeis.edu
}

As a new, uninitiated member of Al Cotton's group in the Summer of 1964, I was assigned the task of learning how to do crystal structures, starting with the synthesis and growth of crystals of rhenium triiodide. The synthesis was troublesome but eventually I got some small needles of ReI3, and collected Weissenberg film packs in order to measure the intensities. I found the space group to be P21 or P21/m. I processed the data after punching the intensities onto cards, and used the reliable Patterson Function to solve the structure...all seemed to go well. But I had a sensible-looking structure that would not refine below a conventional $\mathrm{R}$ of $25-30 \%$. I could not budge it! A highly creative and intelligent visitor to the lab, Leo Becka, looked at the solution, pronounced it likely correct, and suggested that there was a problem with the program...read the FORTRAN, Bruce! Wow. It was about 2000 statements....but not hard to learn how it worked. I found an error that prevented the structure from refining...great! Lesson 1 was that one had to learn to be a program guy in those days. The structure of ReI3 was NOT publishable (decent $\mathrm{R}$ for the time, ca. 8-9\%, but low resolution). So, off to grow more, and good xtals. That took 2.5 years(!), but $\mathrm{R}$ was $4.4 \% .1$ Lesson 2: Thus I found that there was a crystal growth method that was always "guaranteed" to work.2 The other events, all described in detail, are Lesson 3: use programming skills to reduce the number of parameters using rigid phenyl groups (my fifth structure), 3 and carry that on to studies of hindered rotation in crystals. 4 Lesson 4 describes the results following structure determinations of X-ray sensitive cobalt complexes (my sixth structure5) using $\mathrm{CuK} \alpha$ radiation and a lucky conversation with a famous organic chemist Arthur Birch, the ANU School of Chemistry Dean: that encounter set me on a career of 50+ years of studying reactions in crystals. 1. Bennett, M. J.; Cotton, F. A.; Foxman, B. M. Inorg. Chem. 1968, 7, 1563-1569. 2. Cotton, F. A. My Life in Chemistry : More Fun Than Fun; Falvello, L. R.; Foxman, B. M. Murillo, C. A.; Murillo, D. Assoc. Eds.; Elsevier, Waltham, MA, 2014, p.94. 3. Cotton, F. A.; Eiss, R.; Foxman, B. M. Inorg. Chem. 1969, 8, 950-957. 4. Bennett, M. J.; Hutcheon, W. L.; Foxman, B. M. Acta Crystallogr. Sect. A 1975, A31, 488-494. 5. Buckingham, D. A; Foxman, B. M.; Sargeson, A. M.; Zanella, A. J. Am. Chem. Soc. 1972, 94, 1007-1009; Buckingham, D. A.; Clark, C. R.; Foxman, B. M.; Gainsford, G. J.; Sargeson, A. M.; Wein, M.; Zanella, A. Inorg. Chem. 1982, 21, 1986-1997. 